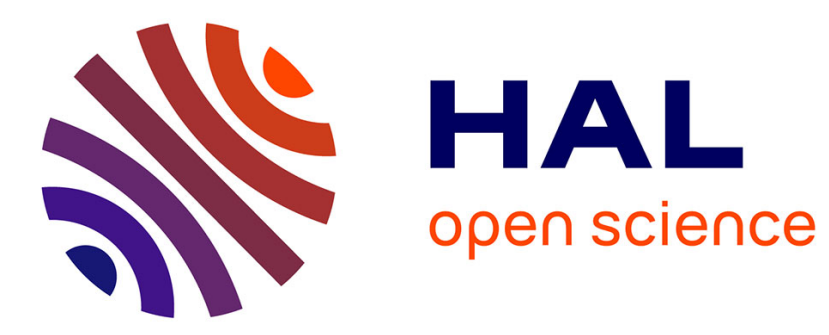

\title{
Uptake of anionic radionuclides onto degraded cement pastes and competing effect of organic ligands
}

\author{
I. Pointeau, N. Coreau, Pascal E. Reiller
}

\section{To cite this version:}

I. Pointeau, N. Coreau, Pascal E. Reiller. Uptake of anionic radionuclides onto degraded cement pastes and competing effect of organic ligands. Radiochimica Acta, 2008, 96 (6), pp.367-374. $10.1524 /$ ract.2008.1503 . cea-00311468

\section{HAL Id: cea-00311468 https://hal-cea.archives-ouvertes.fr/cea-00311468}

Submitted on 18 Aug 2008

HAL is a multi-disciplinary open access archive for the deposit and dissemination of scientific research documents, whether they are published or not. The documents may come from teaching and research institutions in France or abroad, or from public or private research centers.
L'archive ouverte pluridisciplinaire HAL, est destinée au dépôt et à la diffusion de documents scientifiques de niveau recherche, publiés ou non, émanant des établissements d'enseignement et de recherche français ou étrangers, des laboratoires publics ou privés. 


\title{
Uptake of anionic radionuclides onto degraded cement pastes and competing effect of organic ligands
}

\author{
By I. Pointeau ${ }^{1, *, \#, ~ N . ~ C o r e a u ~}{ }^{1}$ and P. E. Reiller ${ }^{2}$ \\ ${ }^{1}$ L3MR, Laboratoire de Mesures et Modélisation de la Migration des Radionucléides, CEA Saclay, Direction de l'Energie Nucléaire/ \\ Département de Physico-Chimie/Service d'Etude du Comportement des Radionucléides, Bât. 450, BP 11, 91191 Gif-sur-Yvette Cedex, France \\ 2 LSRM, Laboratoire de Spéciation des Radionucléides et des Molécules, CEA Saclay, Direction de l’Energie Nucléaire/Département de \\ Physico-Chimie/Service d'Etude du Comportement des Radionucléides, Bât. 391, BP 11, 91191 Gif-sur-Yvette Cedex, France
}

(Received July 2, 2007; accepted in revised form December 13, 2007)

\section{Cement / Degradation / Nuclear waste / Radionuclides / Organic / Uptake}

Summary. Hardened cement pastes (HCP) present a high affinity with a lot of radionuclides $(\mathrm{RN})$ and can be used as waste confining materials in radioactive waste repository. Indeed, in cementitious media, $\mathrm{RN}$ can be removed from solution via (co)precipitation reactions or via sorption/diffusion mechanisms. In this study, the affinity of anionic $\mathrm{RN}\left(\mathrm{Cl}^{-}, \mathrm{I}^{-}\right.$, $\mathrm{SeO}_{3}{ }^{2-}$ and $\mathrm{CO}_{3}{ }^{2-}$ chemical forms) with a CEM-I HCP has been studied $v s$. the degradation of the HCP particles. These $\mathrm{RN}$ are considered as mobile in repository media and it is important to have a set of distribution ratio $\left(R_{\mathrm{d}}\right)$ in cement environment. The $R_{\mathrm{d}}$ values have been measured in batch experiments as a function of the $\mathrm{pH}$, used as the degraded state parameter of the HCP suspensions. The $R_{\mathrm{d}}$ values increase in all cases, from the unaltered state $(\mathrm{pH} 13.3)$ to the altered state of HCP, i.e. until all portlandite is dissolved, corresponding to $\mathrm{pH}$ 12.6. Then, $R_{\mathrm{d}}$ values decrease until degraded states $(\mathrm{pH} 12.0)$, corresponding to the decalcification of the calcium silicate hydrate $(\mathrm{C}-\mathrm{S}-\mathrm{H})$ phases. The behaviour of anionic RN seems to be correlated to the evolution of calcium concentration and is opposed to the evolution of sulphate concentration in solution which could have a competing effect. Comparison is done with the behaviour of caesium and uranium(VI), which is a cationic $\mathrm{RN}$ but has a major negative hydrolysed species at high $\mathrm{pH}$. As awaited, the uranium(VI) behaviour is very different from purely anionic $\mathrm{RN}$ one in accord with spectroscopic analyses from literature works. The $R_{\mathrm{d}}$ values have also been measured for the organic ligands isosaccharinate (ISA) and EDTA. The uptake of ISA can be important and competing effect with the sorption of $\mathrm{SeO}_{3}{ }^{2-}$ has been evidenced in HCP suspensions as a function of the ISA concentration.

\section{Introduction}

In the French design of a deep geological radioactive waste repository, clay media seem favourable host rocks for repos-

\footnotetext{
*Author for correspondence (E-mail: ingmar.pointeau@cea.fr).

\# Present address: Laboratoire de Modélisation des Transferts dans l'Environnement, CEA Cadarache, Direction de l'Energie Nucléaire/Département de Technologie Nucléaire/Service de Modélisation des Transferts et Mesures Nucléaires, Bât. 307, 13108 Saint Paul lez Durance Cedex, France
}

itories as they have interesting properties for confinement (low permeability, high radioactive waste retention capacity ...). Mortar and concrete could be used as container or buffer, and backfill materials of engineered barrier systems between the wastes and the geological medium, at least for B-wastes, which are long-lived intermediate level wastes mainly generated by the facilities associated with the nuclear-fuel cycle and by research establishments. Cement materials will contribute to the retardation of dissolved radionuclides (RN) by the combination of physical transport and chemical interactions. The chemical interactions may retard mobile RN and lower transport rates. Then, it is important to quantify the sorption of RN with hardened cement pastes (HCP).

One of the alkaline cement materials drawbacks is their high leaching rates, which lead to the alteration of the material [1]. In deep clay geological formations, as the permeability of the rock is very low, cement pastes would be much less degraded as the underground water removal will be very slow. Nevertheless, more important leaching phenomena could occur in some cases as in case of borehole crossing accidentally the repository or as in sub-surface radioactive waste repository concepts. Then, it is necessary to quantify the uptake rates of RN not only in the case of unaltered HCP but also for degraded HCP.

The uptake of actinides, lanthanides, and cationic fission and activation products is high in cement environments and is well documented in literature [2,3, and references therein]. Anionic RN behaviour in cement environments has been less investigated as these $\mathrm{RN}$ are more mobile in clay and cement materials than cationic RN. Then, their confinement concept is mostly based on the anionic exclusion properties during the diffusion through clay media. But as ${ }^{36} \mathrm{Cl},{ }^{129} \mathrm{I}$ and ${ }^{79} \mathrm{Se}$ are the main contributors to the final dose in performance assessment calculations [2], it seems important to evaluate the possible contribution of cement materials to the retardation of these $\mathrm{RN}$ in radioactive waste repository. ${ }^{14} \mathrm{C}$ was also studied in this study (as the carbonate form ${ }^{14} \mathrm{CO}_{3}{ }^{2-}$ ) because mortar and concrete materials could also be used in sub-surface graphite waste storage, issued from natural uranium graphite gas nuclear power plants.

In a previous study, we have measured the evolution of the zeta potential $(\zeta)$ of different HCP vs. their degradation 
states [4]. The $\mathrm{pH}$ of the equilibrium solution was considered as the degradation parameter. Two $\mathrm{pH}_{\mathrm{IEP}}(\mathrm{pH}$ of the isoelectric point) were observed with 12.9 and 11.7 average values. Then, it could be of interest to study the affinity of anionic mobile RN vs. the degradation of HCP and its correlation with the evolution of $\zeta$.

A comparison can be done with the behaviour of cationic $\mathrm{RN}$ in order to consolidate the observation for the anionic RN. Caesium is used as a pure cationic RN, as it is only present in cement water under the $\mathrm{Cs}^{+}$form and because ${ }^{137} \mathrm{Cs}$ is a relevant $\mathrm{RN}$ for performance assessment [2]. Uranium(VI) is also studied as it is a cationic $\mathrm{RN}$, as $\mathrm{UO}_{2}{ }^{2+}$, but is supposed to have major negative hydrolysed species at high $\mathrm{pH}$. For $\mathrm{UO}_{2}{ }^{2+}$, the objective is to complete previous results [5] in order to check whether its anionic hydrolysed species have similar behaviour than pure anionic one in cement environment because few points measured on three degraded states in [5] suggest that another comportment occurs.

Organic products are also present in B-wastes and could have an important effect on the immobilization of $\mathrm{RN}$ in HCP media, because of their ability to form complexes with cationic RN, enhancing their solubility or mobility in the cement pore water. They also could be sorbed onto the HCP surface with a competing effect on anionic RN uptake. The influence of organics such as isosaccharinic acid (ISA), the most important degradation product of cellulose, on the behaviour of cationic fission products and actinides has already been studied in cementitious solution and materials [6-11]. The sorption of ISA on undegraded HCP surface has already been observed and measured [12], and its competing effect on anionic species sorption onto HCP has already been observed [13]. In the present study, this effect has been investigated through batch sorption experiments with selenite $\left(\mathrm{SeO}_{3}{ }^{2-}\right)$ in HCP suspensions as a function of ISA and EDTA concentration. Henceforth, the behaviour of anionic organic species with the degradation of HCP has also been measured.

\section{Materials and methods}

\subsection{Cementitious suspensions preparation}

CEM-I, an Ordinary Portland Cement, purchased from " $\mathrm{Ci}$ ment d'Origny" manufacturer, was used. The experimental details of the clinker composition, the cure of the HCP (water/cement ratio of 0.38 ) and the degradation protocol of the paste are detailed in [4]. Briefly, a four years old HCP, setting in saturated portlandite water, has been crushed and different masses of the sieved powder have been put in contact with milliQ water and/or an artificial fresh cement water. The artificial fresh cement water was synthesized dissolving $\mathrm{NaOH}, \mathrm{KOH}$ and $\mathrm{Ca}(\mathrm{OH})_{2}$ in demineralised degassed water. The $\mathrm{pH}$ of this water is about 13.3, and its composition is close to calculated pore water composition of undegraded cement pastes [1]. These equilibrations allow getting about twelve degradation states between $\mathrm{pH} 11.5$ and 13.3. The batches were carried out in $30 \mathrm{~mL}$ polysulfone (PSF) centrifuge tubes (with polypropylene screw closure). All preparations (weighting, batch preparation, and sampling) were performed in a glove box under nitrogen atmosphere to prevent carbonation of the suspensions $\left(p_{\mathrm{CO}_{2}}<1 \mathrm{ppm}\right)$. After two weeks of equilibration under tri-dimensional agitation, the tubes were ultracentrifuged $(50000 \mathrm{~g}$ for $1 \mathrm{~h}$ ) and $1 \mathrm{~mL}$ of solution was sampled and acidified with an Ultrapur $\mathrm{HNO}_{3}$ solution. Then, total concentrations of calcium, chloride and sulphate have been measured by ionic chromatography (Dionex DX-120). The $\mathrm{pH}$ values were measured in the supernatant solution of the batch with a combined microelectrode (Mettler Inlab, electrolyte filling $\mathrm{KCl} 3 \mathrm{M} / \mathrm{AgCl}$ saturated) calibrated at pH 7.01 (phosphate buffer as $\mathrm{KH}_{2} \mathrm{PO}_{4} / \mathrm{Na}_{2} \mathrm{PO}_{4}$ ) and 12.65 (saturated solution of portlandite) at $20^{\circ} \mathrm{C}$. The uncertainty of $\mathrm{pH}$ measurement was estimated to be 0.05 .

\subsection{Organic ligands}

EDTA salt, ethylenediaminetetraacetic acid disodium dihydrate $-\mathrm{C}_{10} \mathrm{H}_{14} \mathrm{~N}_{2} \mathrm{O}_{8} \cdot 2 \mathrm{H}_{2} \mathrm{O}$, was purchased from Fluka (ref. 03679 ) with purity higher than $99 \%$. $\mathrm{Ca}(\mathrm{ISA})_{2}$ was synthesised by lactose alkaline degradation in saturated lime water, as described in [14]. The NaISA form was obtained by treating a solution of dissolved $\mathrm{Ca}(\mathrm{ISA})_{2}(20 \mathrm{~g}$ of solid in $2 \mathrm{~L}$ of Milli-Q water) through a column of cation exchange resin (CHELEX 100, converted to the $\mathrm{Na}^{+}$form with $0.2 \mathrm{M} \mathrm{NaOH}$ solution). Characterisation data of $\mathrm{Ca}(\mathrm{ISA})_{2}$ solid and dissolved NaISA are available in [13].

\subsection{Batch sorption experiments}

After sampling for calcium, chloride and sulphate analyses, the batches were spiked with radioactive solutions. Series of batch sorption experiments were performed for chloride $\left(\mathrm{Cl}^{-}\right)$, iodide $\left(\mathrm{I}^{-}\right)$, selenite $\left(\mathrm{SeO}_{3}{ }^{2-}\right)$ and carbonate $\left(\mathrm{CO}_{3}{ }^{2-}\right)$. Series were also performed with two cationic RN, caesium $\left(\mathrm{Cs}^{+}\right)$and uranium $\left(\mathrm{UO}_{2}{ }^{2+}\right)$. Lastly, a series was done with ISA and two batches were also performed to measure the uptake of EDTA. After equilibration under tri-dimensional agitation for one month ( $\mathrm{Cl}, \mathrm{I}, \mathrm{Se}$, and $\mathrm{C})$, or for two weeks (Cs, U, ISA and EDTA), the suspensions were ultracentrifuged at $50000 \mathrm{~g}$ for $1 \mathrm{~h}$. The supernatants were analysed by liquid scintillation counting in order to determine the residual amount of radioactive tracer or by total organic carbon (TOC-5000, Shimadzu) analysis for ISA and EDTA. Results are expressed as distribution ratio $R_{\mathrm{d}}$ values, which correspond to:

$$
\begin{aligned}
& R_{\mathrm{d}}(\mathrm{mL} / \mathrm{g})=\frac{[\mathrm{RN}]_{\text {sorbed }}(\mathrm{mol} / \mathrm{g})}{[\mathrm{RN}]_{\text {solution }}(\mathrm{mol} / \mathrm{mL})} \\
& =\frac{[\mathrm{RN}]_{\text {initial }}-[\mathrm{RN}]_{\text {solution }}}{[\mathrm{RN}]_{\text {solution }}} \times \frac{\text { solution volume }(\mathrm{mL})}{\text { solid mass }(\mathrm{g})} .
\end{aligned}
$$

The mass of solid used for the $R_{\mathrm{d}}$ calculation is the dry mass determined by ignition at $1000^{\circ} \mathrm{C}$. The same method is applied for the $R_{\mathrm{d}}$ calculation of organic ligand.

Solutions of $\mathrm{Na}^{36} \mathrm{Cl}, \mathrm{Na}^{125} \mathrm{I}, \mathrm{Na}_{2}{ }^{75} \mathrm{SeO}_{3}$ and $\mathrm{Na}_{2}{ }^{14} \mathrm{CO}_{3}$ were used in batch experiments. Average total concentrations of elements before sorption, taking into account carriers, are equal to: $\left[\mathrm{Cl}^{-}\right]=7.6 \times 10^{-8} \mathrm{M},\left[\mathrm{I}^{-}\right]=1.4 \times 10^{-8} \mathrm{M}$, $\left[\mathrm{SeO}_{3}{ }^{2-}\right]=2.2 \times 10^{-8} \mathrm{M}$, and $\left[\mathrm{CO}_{3}{ }^{2-}\right]=10^{-7} \mathrm{M}$. The initial concentration of $\mathrm{CO}_{3}{ }^{2-}$ is lower than the calculated solubility of carbonate in a saturated portlandite water 
(about $6 \times 10^{-6} \mathrm{M}$ ). The calculation has been performed with PHREEQC [15].

${ }^{232} \mathrm{U}\left(\mathrm{UO}_{2} \mathrm{Cl}_{2}\right.$ in $\left.\mathrm{HCl} 2 \mathrm{M}\right)$ is used as tracer. In order to avoid the interferences related to the formation of ${ }^{228} \mathrm{Th}$ and its daughters, the experimental time is limited to 3 weeks for $\mathrm{U}(\mathrm{VI})$ sorption experiments. The stock solution of ${ }^{232} \mathrm{U}$ is purified with a BIORAD AG-1X 8 200-400 mesh resin.

A ${ }^{137} \mathrm{CsCl}$ solution was used and added in the batch experiments with an average concentration before sorption equal to $10^{-9} \mathrm{~mol} \mathrm{~L}^{-1}$.

The initial concentrations of the organic ligands in the batches were $\left[\mathrm{ISA}^{-}\right]=8.5 \times 10^{-4} \mathrm{M}$ and $\left[\mathrm{EDTA}^{-}\right]=$ $1.1 \times 10^{-3} \mathrm{M}$.

\section{Results and discussions}

\subsection{Cementitious materials characterisations}

The cementitious minerals quantifications of the undegraded CEM-I HCP were performed in [4] by differential scanning calorimetry coupled to thermogravimetry (DSC/TG) analysis and by Rietveld's calculations of X-Ray diffraction (XRD) diffractogramms. The analyses shown that portlandite $\left(\mathrm{Ca}(\mathrm{OH})_{2}, 22 \%^{1}\right)$, ettringite $\left(\left[\mathrm{Ca}_{3} \mathrm{Al}(\mathrm{OH})_{6} \cdot 12 \mathrm{H}_{2} \mathrm{O}\right]_{2}\left(\mathrm{SO}_{4}\right)_{3} \cdot 2 \mathrm{H}_{2} \mathrm{O}, 4.7 \%{ }^{1}\right)$ and calcite $\left(\mathrm{CaCO}_{3}, 4.3 \%{ }^{1}\right)$ are the major crystallised cementitious phases. C-S-H phases were also detected (mass estimated to $50 \%$ ), but due to their nano-crystalline structure, only large peaks between 3.05 and $2.83 \AA$ were observed. The evolution of the cement pastes mineralogy with leaching was not analysed in this study and the degradation states were only characterised through the chemical composition of the equilibrium solutions.

\subsection{Evolution of the chemical compositions of the cement waters $v s$. degradation}

The calcium concentration has been measured as it has a strong influence on the uptake of anionic species, allowing the formation of a global positive charge near the surface of cementitious grains when its concentration is sufficiently high. We have already measured and calculated the $\zeta$ evolution of the same CEM-I HCP as a function of its degradation state [4]; two $\mathrm{pH}_{\mathrm{IEP}}$ have been identified (see gray line in Fig. 1). Indeed, $\zeta$ increased from -17 to $+20 \mathrm{mV}$ for $\mathrm{pH}$ decreasing from 13.2 to 12.6 (undegraded HCP states), corresponding to the increase of calcium concentration from $1.1 \times 10^{-3}$ to $2 \times 10^{-2} \mathrm{M}$. Then, $\zeta$ decreases from +20 to $-8 \mathrm{mV}$ for $\mathrm{pH} 12.6$ to 11.0 (degraded HCP states), corresponding to the decrease of calcium concentration from $2 \times 10^{-2}$ to $4 \times 10^{-4} \mathrm{M}$. Hence, $\zeta$ is highly dependent on calcium concentration and for both $\mathrm{pH}_{\mathrm{IEP}}$, the calcium concentration value is about $2-4 \times 10^{-3} \mathrm{M}$. The evolution of the calcium concentration measured in the present study is reported in Fig. 1. One can see that for this sample the first $\mathrm{pH}_{\text {IEP }}$ was also attempted to be about 12.9 and the second about 11.7 .

\footnotetext{
${ }^{1}$ The quantity represents the percent of mass of the mineral in HCP.
}

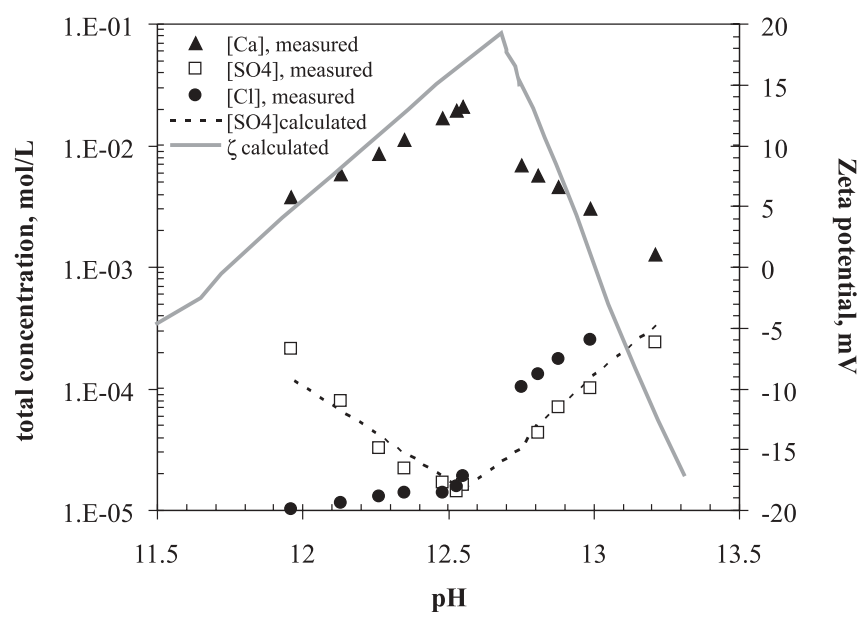

Fig. 1. Evolution of the total concentrations of calcium, sulphate and chloride as a function of $\mathrm{pH}$ in the suspensions of CEM-I HCP powder in contact with demineralised and decarbonated water and/or artificial fresh cement solution. The error bars of the measured concentrations are contained in the size of the symbols. The evolution of $\left[\mathrm{SO}_{4}{ }^{2-}\right]$ resulting from the modelling is also reported. $\zeta$ values are issued from [4].

The concentrations of sulphate have been measured as it could have a competing effect on anionic RN uptake. Indeed, the sorption of $\mathrm{SO}_{4}{ }^{2-}$ on the surface of C-S-H phases has been measured in [16]. The evolution of sulphate monitored in Fig. 1 is well represented by the solubility of ettringite calculated with the PHREEQC code, using the mean solubility product of:

$$
\begin{aligned}
& \mathrm{Ca}_{6}\left[\mathrm{Al}(\mathrm{OH})_{6}\right]_{2}\left(\mathrm{SO}_{4}\right)_{3} \cdot 26 \mathrm{H}_{2} \mathrm{O} \rightleftharpoons \\
& 6 \mathrm{Ca}^{2+}+2 \mathrm{Al}(\mathrm{OH})_{4}{ }^{-}+3 \mathrm{SO}_{4}{ }^{2-}+4 \mathrm{OH}^{-}, \log K=-44.9
\end{aligned}
$$

determined in [17].

From $\mathrm{pH} 13.2$ to 12.6 , the evolution of the sulphate concentration would be in the favour of the uptake of anionic $\mathrm{RN}$ whereas from $\mathrm{pH} 12.6$ to 12.0 , the evolution of sulphate concentration might be unfavourable to the sorption of anionic RN.

Chloride concentration has also been measured in order to determine the total chloride concentration in ${ }^{36} \mathrm{Cl}^{-}$batch sorption experiments. The behaviour of chloride is different from sulphate one as the concentration decreases regularly with the alteration of the HCP. The solubility of the chloride is probably controlled by the Friedel's salt $\left(\mathrm{Ca}_{2} \mathrm{Al}(\mathrm{OH})_{6}(\mathrm{Cl}, \mathrm{OH}) \cdot 2 \mathrm{H}_{2} \mathrm{O}\right)$ as reported in [18]. Nevertheless, chloride has a high solubility and it is difficult to estimate the initial amount of chloride that is present in the HCP as the cement pastes have previously been stored in a saturated portlandite solution where the chloride may have been dissolved and diffused.

\subsection{Behaviour of anionic $\mathrm{RN}$ in cement pastes suspensions vs. degradation}

The sorption kinetics of ${ }^{75} \mathrm{SeO}_{3}{ }^{2-}$, monitored by $R_{\mathrm{d}}$ evolution $v$ s. time, are reported in Fig. 2. For the three degradation states (corresponding to $\mathrm{pH} 13.2,12.4$ and 11.9), long times are required to reach the equilibrium state, almost $30-50$ days. This result suggests that the uptake of $\mathrm{Se}(\mathrm{IV})$ 


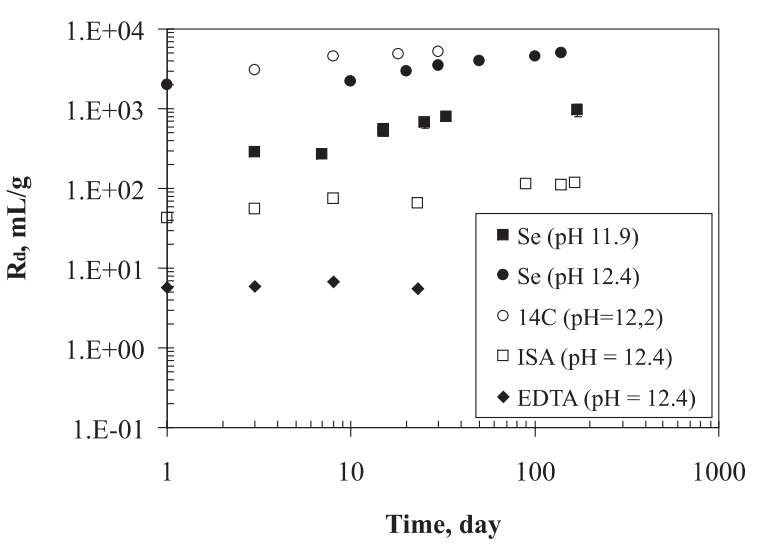

Fig. 2. The uptake kinetic of ${ }^{75} \mathrm{SeO}_{3}{ }^{2-},{ }^{14} \mathrm{CO}_{3}{ }^{2-}$, ISA and EDTA by HCP CEM-I is represented at different degradation states. Kinetic $R_{\mathrm{d}}$ values of ${ }^{75} \mathrm{SeO}_{3}{ }^{2-}$ reported at the degraded state $\mathrm{pH} 12.4$ are issued from [25].

is not only a sorption mechanism on the cement minerals surface but, in addition, this phenomenon could be followed by a diffusion mechanism in the cement minerals structure. 30 days has been selected as the contact time used in the following batch sorption experiments.

Bonhoure et al. [19] have also observed long equilibration times for the uptake of iodide in unaltered HCP suspensions. The authors have measured that, even after 180 days, the $R_{\mathrm{d}}$ values were still increasing: the $R_{\mathrm{d}}$ values were increased by a factor 2 between 7 days and 180 days. No kinetic study of ${ }^{36} \mathrm{Cl}^{-}$sorption has been performed so far in the literature, and the same contact time of 30 days has been applied for the batch sorption experiments.

For ${ }^{14} \mathrm{CO}_{3}{ }^{2-}$ the longest studied time is only 30 days (see Fig. 2) but the major part of the tracer seems sorbed. This experimental time is lower than the one reported in [20], where an increase of the $R_{\mathrm{d}}$ values until 100 days is reported. The uptake mechanism of ${ }^{14} \mathrm{CO}_{3}{ }^{2-}$ is still puzzling. Bayliss et al. suggested that the uptake mechanism was probably an isotopic exchange between ${ }^{14} \mathrm{C}$ and stable carbon of calcite initially present in the materials [20], whereas Noshita et al. [21] have studied the sorption of ${ }^{14} \mathrm{CO}_{3}{ }^{2-}$ on cement minerals and have suggested that it can also sorb on $>\mathrm{SiOCa}^{+}$site on C-S-H surface.

It could be noticed that the main goals of this study was to obtain operational experimental $R_{\mathrm{d}}$ values for a large panel of altered and degraded HCP states. Then, even if the contact time (30 days) is sometimes lower than the required time of equilibrium state, the $R_{\mathrm{d}}$ values can still be used as conservative values for performance assessment calculations.

The measured $R_{\mathrm{d}}$ values of ${ }^{36} \mathrm{Cl}^{-},{ }^{125} \mathrm{I}^{-},{ }^{75} \mathrm{SeO}_{3}{ }^{2-}$, and ${ }^{14} \mathrm{CO}_{3}{ }^{2-}$ are reported in Fig. 3 as a function of the degradation of the HCP. $R_{\mathrm{d}}$ values measured in literature are also reported [19,22-24]. The evolution trends of $R_{\mathrm{d}}$ values $v s$. $\mathrm{pH}$ are similar for all the $\mathrm{RN}$ and two major features can be discriminated during the degradation of the HCP.

Between $\mathrm{pH} 13.2$ and 12.6, when portlandite is still present, $R_{\mathrm{d}}$ values increase and, globally, the affinity order is ${ }^{14} \mathrm{CO}_{3}{ }^{2-}>{ }^{75} \mathrm{SeO}_{3}{ }^{2-}>{ }^{125} \mathrm{I}^{-}>{ }^{36} \mathrm{Cl}^{-}$. For the degraded states under $\mathrm{pH} 12.6$ (total leaching of portlandite), $R_{\mathrm{d}}$ values slightly decrease. The affinity order of RN for the highly degraded HCP is the same than for the first part of the degradation. It is worthy to notice that the $R_{\mathrm{d}}$ values measured

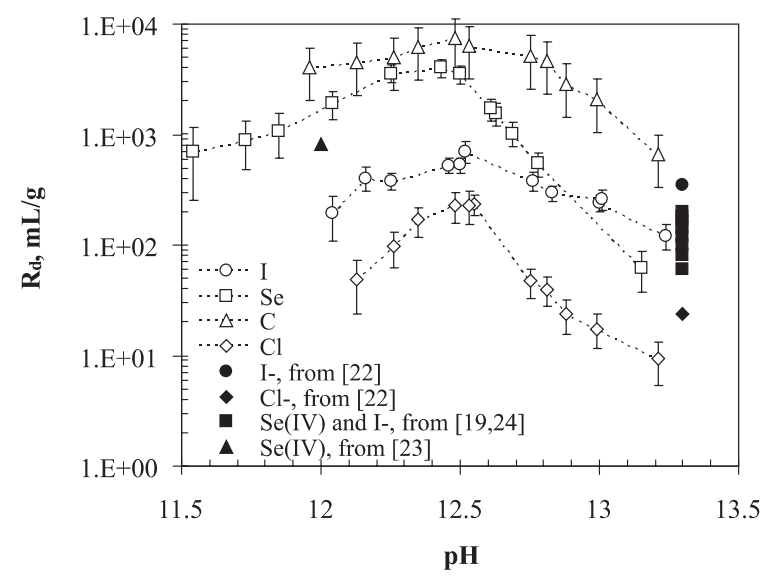

Fig. 3. Evolution of the $R_{\mathrm{d}}$ values of ${ }^{125} \mathrm{I}^{-},{ }^{14} \mathrm{CO}_{3}{ }^{2-},{ }^{75} \mathrm{SeO}_{3}{ }^{2-}$ and ${ }^{36} \mathrm{Cl}^{-}$ in degraded CEM-I HCP suspensions as a function of $\mathrm{pH}$.

for the more degraded state $(\mathrm{pH} 12)$ are always higher than the $R_{\mathrm{d}}$ values measured for the unaltered state $(\mathrm{pH} 13.2)$, which could be used as a conservative value in performance assessment calculations.

This behaviour is well correlated to the evolution of calcium concentration. It seems that the development of positive charge at/near the negative surface charge of HCP allows the uptake of anionic RN. Furthermore, the $R_{\mathrm{d}}$ evolution of anionic RN agrees with the evolution of the concentration of the competing $\mathrm{SO}_{4}{ }^{2-}$ specie, as $R_{\mathrm{d}}$ and $\left[\mathrm{SO}_{4}{ }^{2-}\right]$ are inversely correlated.

Few spectroscopic studies have been performed in literature in order to identify the chemical environment of the sorbed anionic RN in cement materials. Bonhoure et al. [24] have studied by X-ray absorption fine spectroscopy (XAFS) the uptake of Se(IV) oxy-anion by unaltered CEM-I HCP and cement minerals (C-S-H, ettringite ...). They suggested that the coordination sphere of the $\mathrm{SeO}_{3}{ }^{2-}$ entity was maintained upon immobilisation by HCP and non-specific interactions (outer-sphere surface complex) dominate at the given selenite loadings. Macé [25] has measured the $R_{\mathrm{d}}$ values of $\mathrm{Se}(\mathrm{IV})$ on different cement minerals $(\mathrm{C}-\mathrm{S}-\mathrm{H}$, ettringite and hydrogarnet) and has observed that the uptake of $\mathrm{Se}(\mathrm{IV})$ in HCP suspension is controlled by aluminate phases (hydrogarnet and ettringite) rather than $\mathrm{C}-\mathrm{S}-\mathrm{H}$ phases that are minor contributors in the immobilization of Se(IV). Toyohara et al. [26, 27] have identified that a hydrogarnet phase $\left(4 \mathrm{CaO} \cdot \mathrm{Al}_{2} \mathrm{O}_{3} \cdot 13 \mathrm{H}_{2} \mathrm{O}\right)$ controls the uptake of iodide in cement. Bonhoure et al. [19] only obtained extremely weak EXAFS oscillations from $\mathrm{I}^{-}$treated unaltered CEM-I HCP and $\mathrm{CSH}$ samples, which has limited the interpretation of the EXAFS data. These results suggest that the uptake of ${ }^{36} \mathrm{Cl}^{-}$, ${ }^{125} \mathrm{I}^{-}$and ${ }^{75} \mathrm{SeO}_{3}{ }^{2-}$ are the result of electrostatic interactions with the HCP surface, and that no specific chemical adsorption occurs.

\subsection{Behaviour of cationic $R N$ in cement pastes suspensions $v s$. degradation}

The kinetic sorption of uranium(VI) has already been studied in [5], with the same cement materials, until 21 days. The measured $R_{\mathrm{d}}$ values between 9 days and 21 days were similar, suggesting that 9 days was the minimum time re- 
quired to reach a steady state. In the present study, a contact time of 15 days has been used. The same time has been used for caesium.

The uptake of caesium in cement materials has already been measured in literature [28, and references therein]. Its behaviour is opposed to the behaviour of the anionic $\mathrm{RN}$ as $R_{\mathrm{d}}$ always increase from unaltered states to highly degraded state, particularly between $\mathrm{pH} 12.6$ and 11.5 , see Fig. 4 . Between $\mathrm{pH} 13.2$ and 12.6, the $R_{\mathrm{d}}$ values did not decrease as $\mathrm{Na}^{+}$and $\mathrm{K}^{+}$concentrations are very important and compete with $\mathrm{Cs}^{+}$sorption, preventing from high $R_{\mathrm{d}}$ values in undegraded HCP states where $\zeta$ values are negative. The behaviour of U(VI) was also investigated. The objective of this experiment was to investigate the behaviour of a positive cation which has negative species in cement water. Indeed, at $\mathrm{pH} 12, \mathrm{UO}_{2}(\mathrm{OH})_{3}{ }^{-}$and $\mathrm{UO}_{2}(\mathrm{OH})_{4}{ }^{2-}$ are present at 97 and $3 \%$ respectively and at $\mathrm{pH} 13.2$ at 51 and $49 \%$ respectively, see Fig. 5. The speciation calculations were estimated using PHREEQC (with Davies equation) and the data from [29]. Then, one could think that in cement environment, U(VI) would have the same behaviour than anionic RN. Nevertheless, the $R_{\mathrm{d}}$ evolution trend of $\mathrm{U}(\mathrm{VI})$ is close to $\mathrm{Cs}^{+}$one's, see Fig. 4, and then different from purely anionic $\mathrm{RN}$ one. We could observe that during the first stage of the degradation, the $R_{\mathrm{d}}$ values are nearly constant $(1000-4000 \mathrm{~mL} / \mathrm{g})$ and it is only when C-S-H phases control the solubility of calcium in the second part of the degradation that the $R_{\mathrm{d}}$ values highly increase (from 4000 to $200000 \mathrm{~mL} / \mathrm{g}$ ), as for $\mathrm{Cs}^{+}$, whereas $R_{\mathrm{d}}$ values of purely anionic $\mathrm{RN}$ decrease in this $\mathrm{pH}$ range. In [5], batch sorption experiments results showed that $R_{\mathrm{d}}$ measured in C-S-H suspensions were very close to $R_{\mathrm{d}}$ values measured in HCP suspensions with similar $\mathrm{Ca} / \mathrm{Si}$ ratio in the solids. Then, it can be supposed that $\mathrm{C}-\mathrm{S}-\mathrm{H}$ phases contribute to the major part of the U(VI) uptake in HCP. Harfouche et al. [30] have studied the uptake of U(VI) by C-S-H using XAFS. A split equatorial oxygen shell, neighbouring silicon atoms at short and long distances, and neighbouring $\mathrm{Ca}$ atoms were observed. The structural parameters resemble those reported for uranophane $\left(\mathrm{Ca}\left(\mathrm{UO}_{2}\right)_{2}\left(\mathrm{SiO}_{3} \mathrm{OH}\right)_{2} \cdot 5 \mathrm{H}_{2} \mathrm{O}\right)$. One can also remind that the operational solubility limits of U(VI) obtained in $[5,31]$ were comparable to the uranophane solubility calculated from thermodynamic data determined by [32]. It can be supposed that inner-sphere complex formation of

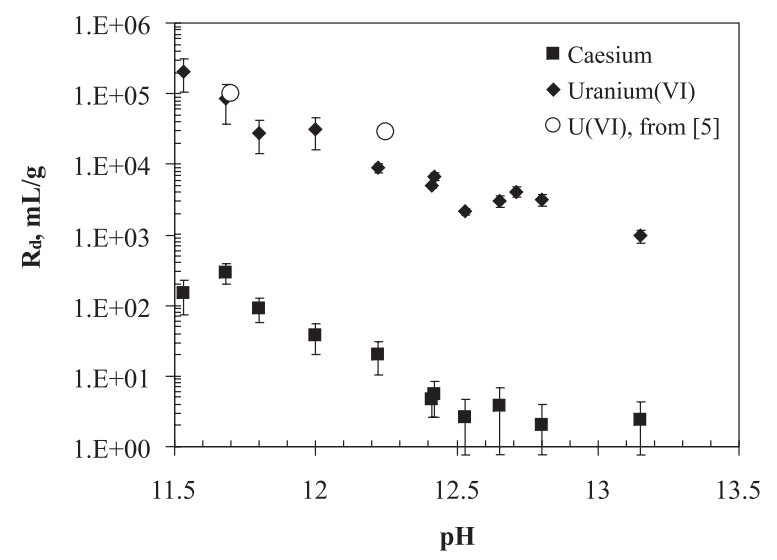

Fig. 4. Evolution of the $R_{\mathrm{d}}$ values of Cs and U(VI) in degraded CEM-I $\mathrm{HCP}$ suspensions as a function of $\mathrm{pH}$.

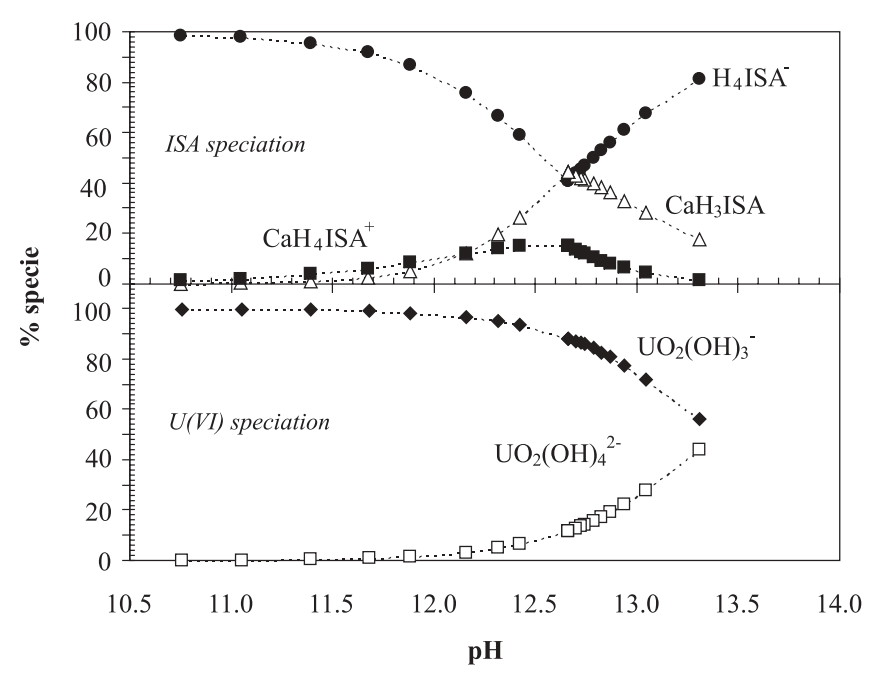

Fig. 5. Speciation of U(VI) and ISA in cement waters as a function of $\mathrm{pH}$ and the associated chemical compositions presented in Fig. 1.

$\mathrm{U}(\mathrm{VI})$ onto $\mathrm{C}-\mathrm{S}-\mathrm{H}$ is the predominant uptake mechanism by adsorption in a first time. Other mechanisms as solidsolution formation could occur after sorption, explaining high $R_{\mathrm{d}}$ values measured for U(VI). This uptake mechanism seems then very different from anions and oxy-anions, where literature spectroscopic investigations suggest the formation of outer-sphere complex to explain the uptake of these RN on HCP surface.

\subsection{Behaviour of organic ligand in cement pastes suspensions $v$ s. degradation}

The kinetic of the sorption mechanism is fast and, after three days, the equilibrium state between the solid phase and the liquid phase is reached (see Fig. 2). The evolution of the uptake of ISA is similar to anionic RN one as a function of the degradation of HCP (see Fig. 6). Indeed, $R_{\mathrm{d}}$ values increased from 4 to $100 \mathrm{~mL} / \mathrm{g}$ for $\mathrm{pH}$ decreasing from 13.2 to 12.5 . Then, $R_{\mathrm{d}}$ decreases from 100 to $25 \mathrm{~mL} / \mathrm{g}$ when $\mathrm{pH}$ decreases from 12.5 to 11.8 .

Speciation calculations on Fig. 5, using data from [33], show that $\mathrm{H}_{4} \mathrm{ISA}^{-}$is the major species over the $\mathrm{pH}$ range 13.2-12.0; $\mathrm{CaH}_{3}$ ISA is the second species, with the highest contribution when the calcium concentration is highest (at $\mathrm{pH}=12.6$ ). The fact that the major species is anionic can explain the similar behaviour of ISA to anionic RN's. EDTA speciation is also dominated by anionic species [33]; $100 \%$ of $\mathrm{CaEDTA}^{2-}$ in degraded HCP water $(\mathrm{pH}=12)$; EDTA $^{4-}$ accounts for $88 \%$ of the speciation in unaltered HCP water $(\mathrm{pH}=13.2)$. The evolution of EDTA affinity seems similar to the ISA one, even if only two $R_{\mathrm{d}}$ values have been measured. $R_{\mathrm{d}}$ values are $0.17^{2} \pm 0.04$ and $11 \pm$ $6 \mathrm{~mL} / \mathrm{g}$ for $\mathrm{pH} 13.2$ and 11.9 respectively, showing a lower affinity than ISA, which has $R_{\mathrm{d}}$ values of $5 \pm 2$ and $61 \pm$ $21 \mathrm{~mL} / \mathrm{g}$, respectively.

As equilibration times are short, shorter than for inorganic anions, uptake of $\mathrm{H}_{4} \mathrm{ISA}^{-}$is probably only controlled

\footnotetext{
${ }^{2}$ The $R_{\mathrm{d}}$ value of EDTA in unaltered HCP suspension has been measured with a higher solid/liquid ratio than for other $R_{\mathrm{d}}$ measurement: $\mathrm{s} / 1=940 \mathrm{~g} / \mathrm{L}$, instead of $1-7 \mathrm{~g} / \mathrm{L}$.
} 


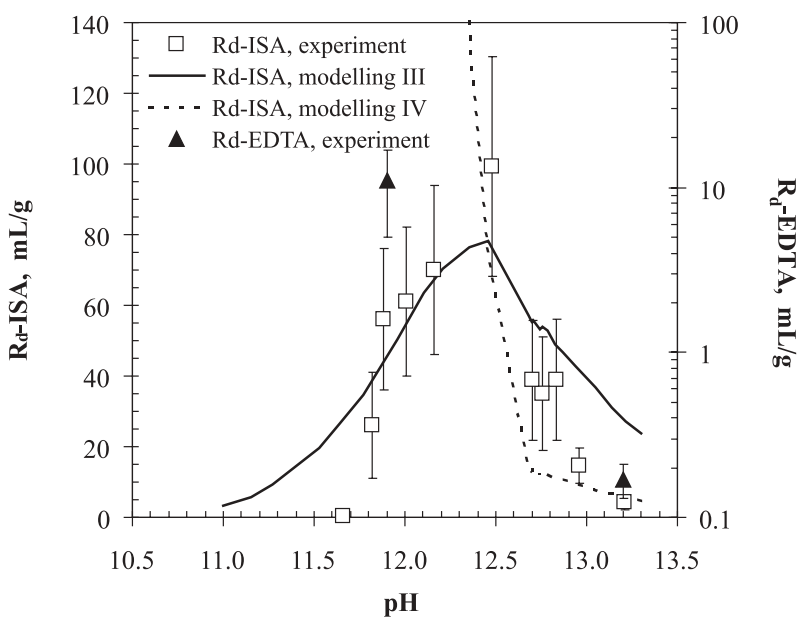

Fig. 6. Evolution of the $R_{\mathrm{d}}$ values of ISA and EDTA in fresh (pH $=13.3)$ and degraded $(\mathrm{pH}=11.9) \mathrm{HCP}$ suspensions. Calculated $R_{\mathrm{d}}$ values of ISA in HCP suspensions are also represented, using surface equilibria III and IV.

by surface mechanism and modelling attempts have been performed. As in [4], this modelling is based on the Diffuse Layered Modelling (DLM) from [34], a surface complexation modelling (SCM). Two surface equilibria have already been proposed for C-S-H surface chemistry $[35,36]$ and have also been used for HCP $\zeta$ calculation [4]:

i) the ionization of the surface sites ( $>\mathrm{SOH})$, mostly through deprotonation:

$$
\begin{aligned}
& >\mathrm{SOH} \rightleftharpoons>\mathrm{SO}^{-}+\mathrm{H}^{+}, \\
& \log K=-12.0,
\end{aligned}
$$

(equilibrium I)

and

ii) the sorption of $\mathrm{Ca}^{2+}$ on the silanol sites, bringing in addition a positive charge through the following equilibrium:

$$
\begin{aligned}
& >\mathrm{SOH}+\mathrm{Ca}^{2+} \rightleftharpoons>\mathrm{SOCa}^{+}+\mathrm{H}^{+}, \\
& \log K=-9.2,
\end{aligned}
$$

(equilibrium II)

The description of the specific adsorption of calcium onto $\mathrm{C}-\mathrm{S}-\mathrm{H}$ can be discussed as Monte Carlo simulations have shown that ordinary electrostatic interactions seem enough to explain the evolution of the effective surface charge of $\mathrm{C}-\mathrm{S}-\mathrm{H}$ particles [37]. Calcium cation overlaps the negative charge of the C-S-H surface by strong physical adsorption resulting from electrostatic interactions. This is why one prefers to talk about global positive charge on/near the surface of HCP and that the SCM proposed in this work has to be considered only as a way for predicting $R_{\mathrm{d}}$ values and does not pretend describing the sorption mechanism that occurs between HCP particles and the organic species. In this first modelling attempt, $\mathrm{H}_{4} \mathrm{ISA}^{-}$is supposed to sorb on the surface sites $>\mathrm{SOH}$ or $>\mathrm{SOCa}^{+}$and two major equilibria could occur:

i) a surface complexation reaction, forming a mixed surface complex:

$$
\begin{array}{lr}
>\mathrm{SOH}+\mathrm{Ca}^{2+}+\mathrm{H}_{4} \mathrm{ISA}^{-} \rightleftharpoons & \mathrm{SOCaH}_{4} \mathrm{ISA}+\mathrm{H}^{+}, \\
\log K=-7.5, & (\text { equilibrium III) }
\end{array}
$$

or

ii) a ligand exchange reaction, forming a simple surface complex:

$$
\begin{aligned}
& >\mathrm{SOH}+\mathrm{H}_{4} \mathrm{ISA}^{-}+\mathrm{H}^{+} \rightleftharpoons \\
& >\mathrm{SH}_{4} \mathrm{ISA}+\mathrm{H}_{2} \mathrm{O} .
\end{aligned}
$$

(equilibrium IV)

The thermodynamic calculations have been performed with PHREEQC. Modelling the sorption of $\mathrm{H}_{4} \mathrm{ISA}^{-}$with $\mathrm{Ca}^{2+}$ on a surface site give $R_{\mathrm{d}}$ values in good agreement with experimental $R_{\mathrm{d}}$ values; all the attempts done with a ligand exchange equilibrium were not satisfying (equilibrium IV). Indeed, when the surface equilibrium constant is adjusted in the case of an unaltered state, it is impossible to obtain the observed decrease of the $R_{\mathrm{d}}$ after the total leaching of the portlandite. Then, the uptake rate of ISA can only be quantified considering the formation of a mixed surface complex as the equilibrium III.

\subsection{Competing effect of ISA on $\mathrm{SeO}_{3}{ }^{2-}$ uptake in cement pastes suspensions}

In this study, the influence of ISA and EDTA has been studied on the uptake of ${ }^{75} \mathrm{SeO}_{3}{ }^{2-}$ by the undegraded $\mathrm{HCP}$ at $\mathrm{pH} 13.2$ and degraded state of HCP at pH 12.0. Batch sorption experiments results (see Fig. 7) show that the uptake of ISA has a competing effect on the uptake of ${ }^{75} \mathrm{SeO}_{3}{ }^{2-}$. Indeed, in unaltered HCP at $\mathrm{pH} 13.2$ and degraded HCP at $\mathrm{pH} 12.0$, the $R_{\mathrm{d}}$ values measured without ISA are divided by a factor of two when the ISA concentration is about $2 \times 10^{-3}$ and $5 \times 10^{-4} \mathrm{M}$, respectively. The proposed explanations of the $R_{\mathrm{d}}$ decrease in presence of ISA are i) a competing effect of the sorption of the negative species $\mathrm{H}_{4} \mathrm{ISA}^{-}$on the HCP surface and/or ii) the complexation of $\mathrm{Ca}^{2+}$ by ISA, forming $\mathrm{CaH}_{3} \mathrm{ISA}$ and $\mathrm{CaH}_{4} \mathrm{ISA}^{+}$complexes, inducing a more negative charge near the surface of the HCP particles and preventing the formation of a mixed surface complex on HCP. Such a modelling attempt does not provide any argument to discriminate between the two hypotheses.

Data are also reported to show the effect of EDTA. For $\mathrm{HCP}$ at $\mathrm{pH} 13.2$, no effect is observed in the limit of the highest studied organic concentration $\left(10^{-3} \mathrm{M}\right)$. An effect is only observed for HCP at $\mathrm{pH} 12.0$ for the highest concentration and it is not possible to extrapolate the feature of the global influence of EDTA.

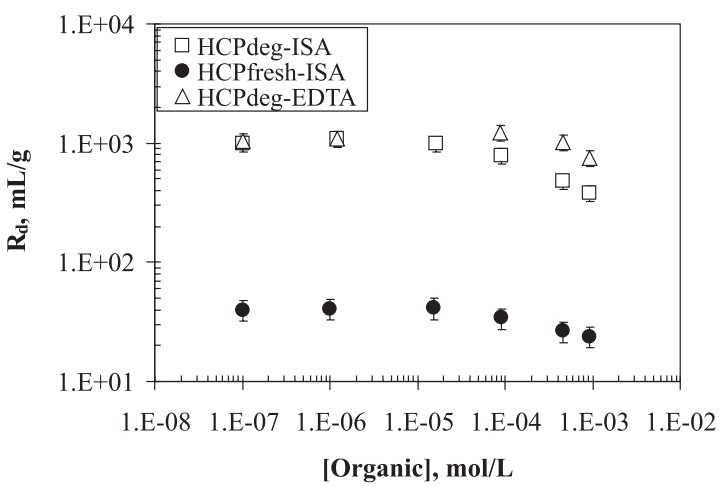

Fig. 7. Evolution of the $R_{\mathrm{d}}$ values of ${ }^{75} \mathrm{SeO}_{3}{ }^{2-}$ in fresh $(\mathrm{pH}=13.3$ ) and degraded ( $\mathrm{pH}=11.9$ ) HCP suspensions as a function of ISA or EDTA concentrations. The $R_{\mathrm{d}}$ values have been measured here after 90 days of contact. 
One can see that organic ligand present in the radioactive waste containers, or produced from this organic matter under alkaline environment as ISA, can have a competing effect on the anionic RN uptake and might be taken into account in the safety performance assessment calculations if their concentration is high.

\section{Conclusion}

A set of experimental distribution ratio $\left(R_{\mathrm{d}}\right)$ has been acquired for $\mathrm{Cl}^{-}, \mathrm{I}^{-}, \mathrm{SeO}_{3}{ }^{2-}$ and $\mathrm{CO}_{3}{ }^{2-}$ in degraded CEM-I $\mathrm{HCP}$ suspensions, as a function of the $\mathrm{pH}$. These data could be used for migration calculation of ${ }^{36} \mathrm{Cl},{ }^{129} \mathrm{I},{ }^{79} \mathrm{Se}$ and ${ }^{14} \mathrm{C}$ in cementitious barriers which could be used in radioactive waste containers and repository. The $R_{\mathrm{d}}$ values increase for the first part of the alteration of the HCP, until the portlandite is buffered (for corresponding $\mathrm{pH} 13.2$ to 12.6 ). Then, the $R_{\mathrm{d}}$ values decrease until $\mathrm{pH}$ 12.0. This behaviour is well correlated to the evolution of the calcium concentration that controls the surface potential near the surface of the HCP particles. The behaviour of the anionic $\mathrm{RN}$ is specific and can not be extrapolated to the behaviour of cationic $\mathrm{RN}$ with anionic species which control their speciation in the $\mathrm{pH}$ range of cementitious materials. The organic ligand initially present or produced in the HLW containers, as ISA, can have a competing effect on the anionic RN uptake and might be taken into account in the performance assessment calculations.

Acknowledgment. Andra, the French National Agency for Radioactive Waste Management, is gratefully acknowledged for having partially financed this work.

\section{References}

1. Berner, U. R.: Evolution of pore water chemistry during degradation of cement in a radioactive waste repository environment. Waste Management 12, 201 (1992).

2. Andra, Dossier 2005 Argile, tome 1/2. Châtenay-Malabry, France (2005).

3. Wieland, E., Van Loon, L. R.: Cementitious near field sorption data base for performance assessment of an ILW repository in Opalinus clay. PSI Report 03-06, Paul Scherrer Institut, Villigen, Switzerland (2002).

4. Pointeau, I., Reiller, P., Macé, N., Landesman, C., Coreau, N.: Measurement and modeling of the surface potential evolution of hydrated cement pastes as a function of degradation. J. Colloid Interf. Sci. 300, 33 (2006).

5. Pointeau, I., Landesman, C., Giffaut, E., Reiller, P.: Reproducibility of the uptake of $\mathrm{U}(\mathrm{VI})$ onto degraded cement pastes and calcium silicate hydrate phases. Radiochim. Acta 92, 645 (2004).

6. Wieland, E., Tits, J., Spieler, P., Dopler, J. P.: Interaction of Eu(III) and Th(IV) with sulphate-resisting Portland cement. Mater. Res. Soc. Symp. Proc. 506, 573 (1998).

7. Wieland, E., Tits, J., Spieler, P., Dopler, J. P.: The effect of $\alpha$ isosaccharinic acid on the stability of and Th(IV) uptake by hardened cement paste. Radiochim. Acta 90, 683 (2002).

8. Tits, J., Wieland, E., Bradbury, M. H.: The effect of isosaccharinic acid and gluconic acid on the retention of $\mathrm{Eu}(\mathrm{III}), \mathrm{Am}(\mathrm{III})$ and Th(IV) by calcite. Appl. Geochem. 20, 2082 (2005).

9. Vercammen, K.: Complexation of calcium, thorium and europium by $\alpha$-isosaccharinic acid under alkaline condition. Dissertation submitted to the Swiss Federal Institut of Technology Zurich. Diss. ETH No. 13466 (2000).
10. Vercammen, K., Glaus, M. A., Van Loon, L. R.: Complexation of Th(IV) and $\mathrm{Eu}(\mathrm{III})$ by $\alpha$-isosaccharinic acid under alkaline conditions. Radiochim. Acta 89, 393 (2001).

11. Warwick, P., Evans, N., Hall, T., Vines, S.: Complexation of Ni(II) by $\alpha$-isosaccharinic acid and gluconic acid from $\mathrm{pH} 7$ to $\mathrm{pH} 13$. Radiochim. Acta 91, 233 (2003).

12. Van Loon, L. R., Glaus, M. A., Stallone, S., Laube, A.: Sorption of isosaccharinic acid, a cellulose degradation product on cement. Env. Sci. Technol. 31, 1243 (1997).

13. Pointeau, I., Hainos, D., Coreau, N., Reiller, P.: Effect of organics on selenite uptake by cementitious materials. Waste Management 26, 733 (2006).

14. Whistler, R. L., BeMiller, J. N.: " $\alpha$ ”-D-Isosaccharino-1,4-lactone. Action of lime water on lactose. In: Methods in Carbohydrate Chemistry, Vol. 2: Reactions of Carbohydrates. (Wolfrom, M. L., BeMiller, J. N., eds.) Academic Press, New York (1963).

15. Parkhurst, D. L., Appelo, C. A. J.: Water-Resources Investigations Report 99-4259, U.S. Geological Survey, Lakewood, CO, USA (1999).

16. Barbarulo, R., Peycelon, H., Prene, S.: Experimental study and modelling of sulfate sorption on calcium silicate hydrates. $13^{\text {th }}$ French-Polish Seminar on Reactivity of Solids, Cluny, France (2003), vol. 28, p. 5.

17. Perkins, R. B., Palmer, C. D.: Solubility of ettringite at $5-75^{\circ}$ C. Geochim. Cosmochim. Acta 63, 1969 (1999).

18. Birnin-Yauri, U. A., Glasser, F. P.: Friedel's Salt, $\mathrm{Ca}_{2} \mathrm{Al}(\mathrm{OH})_{6}{ }^{-}$ $(\mathrm{Cl}, \mathrm{OH}) \cdot 2 \mathrm{H}_{2} \mathrm{O}$ : its solid solutions and their role in chloride binding. Cem. Concr. Res. 28, 1713 (1998).

19. Bonhoure, I., Scheidegger, A. M., Wieland, E., Dähn, R.: Iodine species uptake by cement and CSH studied by I $K$-edge X-ray absorption spectroscopy. Radiochim. Acta 90, 647 (2002).

20. Bayliss, S., Ewart, F. T., Howse, R. M., Smith-Briggs, J. L., Thomason, H. P., Willmott, H. A.: The solubility and sorption of lead210 and carbon-14 in a near-field environment. Mater. Res. Soc. Symp. Proc. 112, 33 (1988).

21. Noshita, K., Nishi, T., Matsuda, M., Izumida, T.: Sorption mechanism of carbon-14 by hardened cement paste. Mater. Res. Soc. Symp. Proc. 412, 435 (1996).

22. Jakob, A., Sarott, F.-A., Spieler, P.: Diffusion and sorption on hardened cement pastes - experiments and modelling results. PSI Report 99-05, Paul Scherrer Institut, Villigen, Switzerland (1999).

23. Johnson, E. A., Rudin, M. J., Steinberg, S. M., Johnson, W. H.: The sorption of selenite on various cement formulations. Waste Management 20, 509 (2000).

24. Bonhoure, I., Baur, I., Wieland, E., Johnson, C. A., Scheidegger, A. M.: Uptake of Se(IV/VI) oxyanions by hardened cement paste and cement minerals: an X-ray absorption spectroscopy study. Cem. Concr. Res. 36, 91 (2006).

25. Macé, N.: Influence de la température sur la rétention du sélénite par une pâte de ciment altérée et par ses phases pures constitutives. Thesis submitted to the Paris XI University. Orsay, France (2006).

26. Toyohara, M., Kaneko, M., Ueda, H., Mitsutsuka, N., Fujihara, H., Murase, T., Saito, N.: Iodine sorption onto mixed solid alumina cement and calcium compounds. J. Nucl. Sci. Technol. 37, 970 (2000).

27. Toyohara, M., Kaneko, M., Mitsutsuka, N., Fujihara, H., Saito, N., Murase, T.: Contribution to understanding iodine sorption mechanism onto mixed solid alumina cement and calcium compounds. J. Nucl. Sci. Technol. 39, 950 (2002).

28. Ochs, M., Pointeau, I., Giffaut, E.: Caesium sorption by hydrated cement as a function of degradation state: experiments and modelling. Waste Management 26, 725 (2006).

29. Guillaumont, R., Fanghänel, T., Fuger, J., Grenthe, I., Neck, V., Palmer, D. A., Rand, M. H.: Update on the Chemical Thermodynamics of Uranium, Neptunium, Plutonium, Americium and Technicium. Elsevier, Amsterdam (2003).

30. Harfouche, M., Wieland, E., Dähn, R., Fujita, T., Tits, J., Kunz, D., Tsukamoto, M.: EXAFS study of U(VI) uptake by calcium silicate hydrates. J. Colloid Interf. Sci. 303, 195 (2006).

31. Ewart, F. T., Smith-Briggs, J. L., Thomason, H. P., Williams, S. J.: The solubility of actinides in a cementitious near-field environment. Waste Management 12, 241 (1992). 
32. Pérez, I., Casas, I., Martín, M., Bruno, J.: The thermodynamics and kinetics of uranophane dissolution in bicarbonate test solution. Geochim. Cosmochim. Acta. 64, 603 (2000).

33. Hummel, W., Anderegg, G., Rao, L. F., Puigdomènech, I., Tochiyama, O.: Chemical thermodynamics of compounds and complexes of $U, N p, P u, A m, T c, S e, N i$ and $Z r$ with selected organic ligands. Elsevier, Amsterdam (2005).

34. Dzombac, D. A., Morel, F. M. M.: Surface Complexation Modeling: Hydrous Ferric Oxide. Wiley-Interscience, New York (1990).
35. Viallis-Terrisse, H., Nonat, A., Petit, J.-C.: Zeta-potential study of calcium silicate hydrates interacting with alkaline cations. J. Colloid Interf. Sci. 244, 58 (2001).

36. Pointeau, I.: Etude mécanistique et modélisation de la rétention de radionucléides par les silicates de calcium hydratés (CSH) des ciments. Thesis submitted to the University of Reims ChampagneArdenne, France (2000).

37. Labbez, C., Nonat, A., Pochard, I., Jönsson, B.: Experimental and theoretical evidence of overcharging of calcium silicate hydrate. J. Colloid Interf. Sci. 309, 303 (2007). 